\title{
Dying and death in Nigeria - a social commentary
}

\section{Commentary}

The Scripture says, "There are a time to be born and a time to die". This saying reminds everyone of our mortality and the debt. A discourse about dying and death in most human society including Nigeria is a taboo. In ancient days and during war in Yoruba land, an unwise emissary from war zone that comes home to announce the demise of a War General unknowingly request his personal death warrant. Any discussion around dying and death in most of the African culture is tantamount to an invite of spirit of death - a bad omen and wishing somebody dead. The modern society dramatizes death a lot on televisions and films. This is the reason young kids only experience death as violence but never in real life. To the extent that children are not usually encouraged to attend funerals in order to protect their emotions and unconsciously underrating their understanding of death issues.

\section{Do Nigerians experience good death?}

Death is a debt for everyone. Unless an individual dies suddenly by gun shot or involved in a Plane crash, many individual would die slowly of chronic illness. It should therefore be our collective responsibility to accompanying those "walking through the valley of death" as we cannot fathom who would be there for us in the future. Good death could be regarded as a peaceful, painless, smooth transition and dying with dignity.

\section{The question is how many Nigerians enjoy such natural phenomenon?}

Poverty, lack of basic medications including strong analgesics (Opioids) to relief pains and the rapidly collapsing family support for patients on death bed is some of the factors making good death a challenge. For patients and families suffering from life - threatening or life-limiting illnesses, the health care professionals' advice them to take the patient home for "there is nothing more we can do again". So how do the dying patients experience good death at home in a society where we have institutionalized death in the hospitals and developed pathological fear to witnessing death of loved ones at home. Hospitals have become the preferable place of death in Nigeria unlike in advance countries. The rich ones are the worst affected as we usually read some egocentric advertised obituaries ' died in UK or USA hospital'.

Lest we forget that our forefathers enjoyed dying peacefully in their huts and homes surrounded by their children and families. I could still remember when the whole world stood still and many faithfull's including the CNN was keeping vigils near Late Pope John II home when with dignity he refused further admissions into the hospital. Nigerians and other Africans need to go back to the era of providing good death at home just like some countries in developed world.

I can imagine people thinking that Hospice and palliative care is alien or foreign to our culture and doubt the concept. The Nigeria culture, several decades ago in the villages had a communal ways of taking care of the dying. I could still recollect vividly the old dying women in their dark small room with pinhole - poorly ventilated window. Their children based in far away cities and in Diaspora. Only
Volume I Issue I - 2017

\author{
Folaju O Oyebola \\ Head of Department at the Federal Medical Centre Abeokuta, \\ Nigeria
}

Correspondence: Folaju O Oyebola, Head of Department at the Federal Medical Centre Abeokuta, Consultant in Pain and Palliative Medicine, Nigeria, Email fooyebola@yahoo.com

Received: March 27, 2017 | Published: March 28, 2017

the neighbor's support, assist and come around in the morning to exchange pleasantries; 'Mama how are you feeling today?' 'What can I do for you?' 'What type of food do I prepare for you?' 'Can I come in to sweep your room?' 'Could you please bring out your clothes for me to help you wash?'

Palliative care is regarded as an approach to improve the quality of life of patients and families suffering from life-threatening conditions by providing pain and symptom control besides addressing their social-economic, emotional, cultural and spiritual issues. It is an arm of medical field that provides holistic approach to the needs of both the patients and families. It is not peculiar to an End - of - Life care alone as it is recommended to commence at the point of diagnosis in any chronic disease condition as a continuum of care. It is applicable in disease conditions like cancer, stroke, end-stage renal, liver, diabetes, sickle-cell crises and HIV/AIDS. Impeccable assessments of patients may reveal physical pains, social, emotional and spiritual distress that often results to "total pains". Most clinical services often focus mainly on the physical aspect of the disease. There is need to approach every patient in a three-dimensional (3D) model - the Body, Mind and Spirit.

The contemporary medical practice including the WHO emphasizes and demands holistic care model of assessment and treating both the disease and the patient, not either of the two. A dying patient and family experiencing social, emotional and spiritual distress and pains require assistance from a multidisciplinary team of health care professionals to handle these three domains. Surprisingly, when a soul is being midwife into this world many people including the families and health care professionals wait patiently and anxiously in anticipation. Ironically when that same soul is passing on to the other world is left alone and abandoned. The patients and families are saddled with burdens of uncontrolled pains, fear, anxiety, depression, loss of dignity and existential issues.

What are the roles of patients, families, community, religious organizations, health care providers, carer, hospitals and most importantly the government in the provision of good death to dying Nigerians? It is a pity this concept and philosophy require much more sensitization and advocacy to Nigerians to ensure a dignified death for the citizenry.

It is difficult to rationalize lack of or inadequate preparation for deaths, as it is often the case in our society. You inform a patient of an impending death and he looks at you as an insane person wishing 
him dead. His natural response would be 'I reject it in Jesus name' and next time you come to review, he would pretend he is deep asleep and does not want to be disturbed. Per adventure the family got to know first of the impending death they would inform the health care professionals not to let the patient know that death is already knocking on the door - 'conspiracy of silence'. All in attempt to protect the patient fearing the bad news might even kill the patient faster rather than empowering the patient to prepare for the journey ahead.

Hospice and Palliative care was introduced to Nigeria since 1993,widely embraced in 2007 but still facing a lot of challenges in making it accessible to the over 180 million of Nigerians. Some of which include lack of recognition, manpower, funding, education and its non-inclusion in the national health policy by the government as prescribed by the World Health Organization (WHO). Nevertheless, as of today there is a paradigm shift and there are about eighteen health facilities in the country offering palliative care services.

\section{Acknowledgements}

None.

\section{Conflict of interest}

The author declares no conflict of interest. 